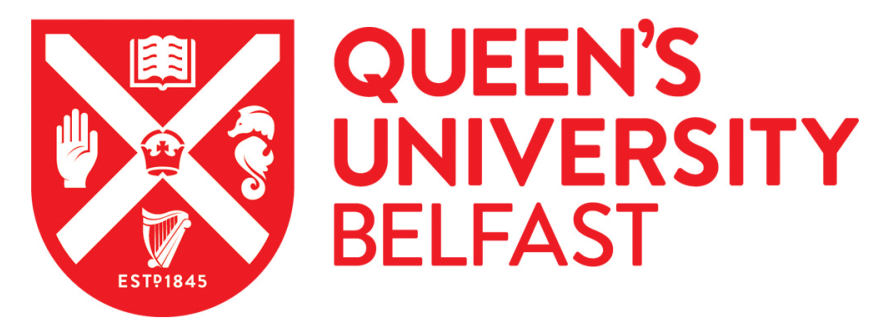

\title{
A 20-year analysis of reported food fraud in the global beef supply chain
}

Robson, K., Dean, M., Brooks, S., Haughey, S., \& Elliott, C. (2020). A 20-year analysis of reported food fraud in the global beef supply chain. Food Control, [107310]. https://doi.org/10.1016/j.foodcont.2020.107310

\author{
Published in: \\ Food Control
}

Document Version:

Peer reviewed version

Queen's University Belfast - Research Portal:

Link to publication record in Queen's University Belfast Research Portal

Publisher rights

(C) 2020 Published by Elsevier Ltd.

This manuscript is distributed under a Creative Commons Attribution-NonCommercial-NoDerivs License

(https://creativecommons.org/licenses/by-nc-nd/4.0/), which permits distribution and reproduction for non-commercial purposes, provided the author and source are cited.

\section{General rights}

Copyright for the publications made accessible via the Queen's University Belfast Research Portal is retained by the author(s) and / or other copyright owners and it is a condition of accessing these publications that users recognise and abide by the legal requirements associated with these rights.

Take down policy

The Research Portal is Queen's institutional repository that provides access to Queen's research output. Every effort has been made to ensure that content in the Research Portal does not infringe any person's rights, or applicable UK laws. If you discover content in the Research Portal that you believe breaches copyright or violates any law, please contact openaccess@qub.ac.uk. 


\section{Journal Pre-proof}

A 20-year analysis of reported food fraud in the global beef supply chain

Kelsey Robson, Moira Dean, Stephanie Brooks, Simon Haughey, Christopher Elliott

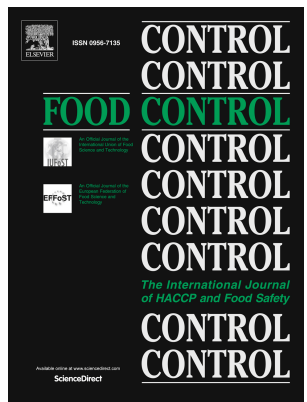

PII: S0956-7135(20)30226-7

DOI: $\quad$ https://doi.org/10.1016/j.foodcont.2020.107310

Reference: JFCO 107310

To appear in: Food Control

Received Date: 18 November 2019

Revised Date: 10 February 2020

Accepted Date: 21 April 2020

Please cite this article as: Robson K., Dean M., Brooks S., Haughey S. \& Elliott C., A 20-year analysis of reported food fraud in the global beef supply chain, Food Control (2020), doi: https://doi.org/10.1016/ j.foodcont.2020.107310.

This is a PDF file of an article that has undergone enhancements after acceptance, such as the addition of a cover page and metadata, and formatting for readability, but it is not yet the definitive version of record. This version will undergo additional copyediting, typesetting and review before it is published in its final form, but we are providing this version to give early visibility of the article. Please note that, during the production process, errors may be discovered which could affect the content, and all legal disclaimers that apply to the journal pertain.

() 2020 Published by Elsevier Ltd. 
Title: A 20-year analysis of reported food fraud in the global beef supply chain

\section{Authors names and affiliations:}

1. Miss Kelsey Robson ${ }^{a, b}$

Krobson02@qub.ac.uk

2. Professor Moira Dean ${ }^{a}$

Moira.dean@qub.ac.uk

3. Dr. Stephanie Brooks ${ }^{a}$

s.brooks@qub.ac.uk

4. Dr. Simon Haughey ${ }^{a}$

s.a.haughey@qub.ac.uk

5. Professor Christopher Elliott ${ }^{a}$

Chris.elliott@qub.ac.uk

a Institute for Global Food Security, Queen's University Belfast, University Road, Belfast,

BT7 1NN, Northern Ireland, United Kingdom

${ }^{\mathrm{b}}$ ABP Food Group, $14^{\text {th }}$ Castle Street Ardee Co. Louth

\section{Abstract}

Background:

The Horsemeat Scandal of 2013 highlighted vulnerabilities within the European beef supply chain. The report resulted in mass product recalls across Europe, a downturn in beef sales, and subsequent economic losses for genuine actors in the supply chain. The aim of this review was to improve understanding of beef supply chain vulnerability via the use of trend analysis, to enable the formulation of strategies that may help in the prevention and detection of fraud in beef products, and facilitate greater protection for consumers and industry in the future.

Scope and Approach:

Relevant Food notifications published in the Rapid Alert System for Food and Feed (RASFF) and HorizonScan in 1997-2017 were extracted and analysed to determine their overall pattern.

Frauds/adulterations were categorised by the type of fraud, their location in the food production chain, the notifying country and the origin of the food.

Conclusions: 
Counterfeiting was the most common type of fraud in the beef industry; it accounted for $42.9 \%$ of all reports documented. When reports were classified by area in the supply chain in the report occurred, $36.4 \%$ of all cases were attributed to primary processing, of which $95.5 \%$ were counterfeiting cases. Counterfeiting included products manufactured/packed on unapproved premises, or without appropriate inspection or documentation, as well as products issued with fraudulent health certificates. Thus we conclude counterfeit product was found to be the biggest threat to the beef supply chain in relation to fraud type.

\section{Keywords}

Food Fraud

Beef

Supply Chain

RASFF

HorizonScan

Highlights

- 413 fraud reports in the beef supply chain were identified between 1997-2017.

- Counterfeiting accounted for $42.9 \%$ of identified fraud.

- Primary processing is the most vulnerable area, accounting for $35.8 \%$ of reports.

\section{Funding}

This review is funded by the European Institute of Innovation and Technology (EIT) and ABP Food Group. 


\section{Introduction}

In 2013, the European Horsemeat Scandal highlighted vulnerabilities within the beef supply chain

(Elliott, 2014; Manning, Smith, \& Soon, 2016). This scandal resulted in product recalls, with a serious impact on the sale of ground beef, and huge economic losses for defrauded companies (Regan et al., 2015; van Ruth, Huisman, \& Luning, 2017). Widespread media coverage of the event contributed further damage to consumer trust and brought into question the integrity of the beef supply chain (Manning, 2016). Such scandals have increased awareness of food fraud, and as a result, has brought attention to vulnerabilities for the food industry (Huck, Pezzei, \& Huck-Pezzei, 2016; Spink, Moyer, \& Speier-Pero, 2016).

At present, there is no harmonized definition for food fraud in the European Union (EU). However, it is commonly accepted that the term 'food fraud' covers any violation of food law that is an intentional and deceptive misrepresentation of food for financial gain (van Ruth et al., 2017; European Commission, 2018). Spink and Moyer (2011) have elaborated on this definition and describe seven types of food fraud: adulteration, tampering, over-run, theft, diversion, simulation, and counterfeit. However, existing databases that monitor food fraud Such as the Rapid Alert System for Food and Feed (RASFF) and HorizonScan have their own categorizations (Bouzembrak et al., 2018). RASFF has six categorizes for fraud (Improper, fraudulent, missing or absent health certificates; illegal importation; tampering; improper, expired, fraudulent or missing common entry documents or import declarations; expiration date; mislabeling) as does HorizonScan (Adulteration/substitution, fraudulent health certificate/documentation, produced without inspection, unapproved premises, expiry date changes, unauthorized/ unsuitable transport). Discrepancies in these categorizations can create ambiguity and confusion among researchers. 
While the Horsemeat Scandal could be considered the most notable food fraud scandal associated with beef, there is an extensive history of beef-related food fraud (Tähkäpää et al.,2015). Including the 2005 Chinese case where an unauthorized colorant, Sudan red was used in meat products (Jia \& Jukes, 2013). The 'rotten meat scandal' broke in 2006, where approximately 150 tons of rotten meat was distributed to restaurants across Germany (Bosley, 2007). The Horsemeat Scandal in 2013 mentioned above.

'Operation weak flesh' in 2017 that uncovered bribery among high-level Brazilian government officials, including inspectors, politicians, and even the President. This corruption enabled the distribution of rotten meat into the food chain and the overlooking of unsanitary hygiene practices (Haynes \& Spagnuol, 2017). In 2018, a Belgian meat scandal occurred. The Belgian case saw the fabrication of expiration dates the alleged mislabeling of conventional meat as 'organic', as well as meat intended for animal feed being directed into the human food chain (Green, 2018; Grobe, 2018).

While a number of fraud incidents have been documented, they may only represent a small fraction of the true number of incidents. Undetected acts of fraud are affecting the food supply chain continuously. The Grocery Manufacturers' Association estimates that global food fraud costs between $\$ 10$ billion and $\$ 15$ billion per year; equating to an estimated $10 \%$ of all food products sold commercially (Johnson, 2014; Manning, 2016). Others such as PricewaterhouseCoopers (PWC) estimate much higher, $\$ 30$ to $\$ 40$ billion annually (PricewaterhouseCoopers, 2017). The demand of meat products is high and as a result, meat is one of the most highly-priced food commodities; therefore, a prime target for food fraud (Cawthorn, Steinman, \& Hoffman, 2013). The food industry is vulnerable to the actors in the supply chain (suppliers, farmers and other manufacturers), who may be driven to commit fraud by a variety of factors, such as the need to compete with other businesses, or those motivated by economic gain (Manning, 2016). To protect itself and consumers, the beef industry needs a better understanding of the vulnerabilities within the beef supply chain. 
Both highly publicized scandals and continual underhanded acts of fraud can endanger public health. However, food fraud is unconventional, therefore health effects of food fraud are difficult to detect (Tähkäpää et al., 2015). There are cases of food fraud which have resulted in acute health effects and fatalities. Arguably the most widely-known report would be the melamine scandal in 2008. In this casereport adulterated baby formula poisoned hundreds of thousands of babies and is confirmed killing at least six babies (Xiu \& Klein, 2010). Long-term, chronic exposure to food fraud via consumption of low dose toxic or carcinogenic contaminants in food, or the exclusion of important vitamins or preservatives could put consumers at risk of chronic health impacts (Spink \& Moyer, 2011). The potential health effects of food fraud in the beef supply chain are unknown and can only be determined when contaminates are found. This is a reactive system as by the time contaminants are discovered, it is often too late to mitigate risk against human exposure.

Food fraud protection systems must start with prevention in order to gain an understanding of potential risks and vulnerabilities before executing prevention steps (Spink \& Moore, 2011; Moore et al., 2012). Traditional food protection systems that are used by the food industry to mitigate known food safety risk such as microbiological contamination, work in a cyclical system of prevention, intervention and response (Acheson 2007; Food and Drug Administration, 2007; United States Government Accountability Office, 2008, as cited in Moore, Spink \& Lipp, 2012). As the risks of food safety are known, prevention is the first step in this system. However, when it comes to food fraud the adulterant is often unknown, as a result current food protection systems are not designed and do not work to detect an infinite number of unknown adulterants (Moore et al., 2012).

As many experts have acknowledged, a thorough understanding of food fraud should begins with a review of previous reports (Moore et al., 2012; Tähkäpää et al., 2015; Zhang and Xue, 2016; Bouzembrak 
et al., 2018). Reviewing historical food fraud reports within supply chains allows one to understand where and how fraud is occurring.

RASFF, HorizonScan, European Media Monitor (EMM)and Decernis are databases which collect then store information on global food fraud and food safety reports (Bouzembrak et al., 2018). This review will use information from two databases: RASFF and HorizonScan. RASFF was selected for use in this review as it has been used in multiple studies that have focused on trending and analyzing food fraud, previously (Tähkäpää et al., 2015; Marvin et al., 2016). HorizonScan is widely used in the largely used by industry throughout the EU.

RASFF was launched as part of a gentlemen's agreement in 1979 with the intention of generating swift information exchange on food and feed related health risks between EU member states (European Commission, 2009). The database is now maintained by the European Commission (EC) under regulation EC/178/2002, and information on RASFF is exchanged among member states, who are legally obliged to report information concerning direct and indirect risks to human health from food or feed (European Food Safety Authority (EFSA), 2010). RASFF database provides information on each report recorded, including the type and date of notification, the reason for notification, the hazard(s), the nature of the product involved, the country of notification, and the country of origin (EFSA, 2010; Djekic, Jankovic \& Rajkovic, 2017).

HorizonScan is largely used by industry throughout the EU and is operated by the Food and Environment Research Agency (Fera) in the UK, as a privatized subscription based system, and monitors safety and integrity issues of food commodities globally via daily collection of data from over 90 sources (FERA, 2018). HorizonScan accommodates demands for transparency and accountability within companies with 
consumer and regulatory requirements across the ingredient supply chain (FERA, 2018). Furthermore, HorizonScan risk assesses and analyses trends in reports to identify potential food safety threats before they escalate to larger problems/risks with the food supply chain (Fera, 2018).

Fraud related reports in the beef supply chain documented in HorizonScan and RASFF over the past 20 years were extracted, analysed and trended to determine vulnerabilities. Trend analysis was used to identify the most common types of fraud and areas of vulnerability within the beef chain, with the view that future research could determine tangible prevention and detection strategies for implementation in beef industry. This would enable the industry to better protect their business and consumers from food fraud.

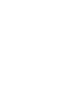

\section{Approach}

\subsection{Extraction and Sorting}

Data spanning $1^{\text {st }}$ January 1997 to $31^{\text {st }}$ December 2017 was exported from the RASFF and HorizonScan online portals into an Excel file. RASFF search criteria included:

1) Product category: animal by-products, feed additives, feed and food producing animals, meat and meat products (other than poultry)

2) Hazard category: adulteration/ fraud, poor and insufficient controls, residues of veterinary medical products

3) keywords: cattle, beef, and bovine.

HorizonScan searches were completed via category searches of meat which included:

1) bovine (beef, veal, cow),

2) meat, minced, ground - bovine (beef, veal, cow), 
3) offal - bovine (beef, veal, cow),

4) fat -bovine (beef, veal, cow),

and advanced keyword searches of beef, cattle and veal.

After all reports had been retrieved, reports were extracted and recorded if they met two selection criteria. For inclusion, the report had to:

1) Relate to beef and beef products and

2) Be considered a food fraud report on either RASFF or HorizonScan

Reports from both systems were reviewed and sorted by predefined categories/criteria provided by RASFF and HorizonScan and included:

$$
\text { - Date }
$$

- Country of Origin

- Subject/ Reason for Notifying

- Country of Notification

- Hazard

In order to facilitate analysis, additional columns were added to the excel spreadsheet:

- Source: RASFF or HorizonScan, including the reference number if report was derived from RASFF.

- Fraud Type as defined by Spink and Moyer (2011) in Table 1. As there are no legal definitions for types of food fraud, therefore reports derived from RASFF and HorizonScan were grouped based on 'fraud type' against the definitions as detailed by Spink and Moyer (2011). However, it should be noted that reports sometimes overlapped multiple fraud types. For example, if a report included adulteration such as species substitution, it was assumed that the product was 

report was recorded once for each type of fraud stated; each type of fraud had to be explicitly stated in RASFF or HorizonScan for it to be recorded.

Table 1. Food fraud types as categorized by Spink and Moyer (2011)

\begin{tabular}{|c|}
\hline Adulteration \\
\hline $\begin{array}{l}\text { A component of the finished product is fraudulent. This category includes substitution, dilution } \\
\text { and unapproved enhancements. }\end{array}$ \\
\hline Counterfeiting \\
\hline $\begin{array}{l}\text { All aspects of the fraudulent product and packaging are fully replicated. Which could include } \\
\text { property infringement, copies of popular food produced without the same food safety } \\
\text { assurances. This category refers to illegal production. }\end{array}$ \\
\hline Diversion \\
\hline $\begin{array}{c}\text { The sale or distribution of legitimate products outside of intended markets. Such as grey and } \\
\text { black market. }\end{array}$ \\
\hline Tampering \\
\hline $\begin{array}{l}\text { Legitimate product and packaging are used in fraudulent ways, such as intentional mislabeling } \\
\text { and changes in expiry information. }\end{array}$ \\
\hline Theft \\
\hline Legitimate product is stolen and passed off as legitimately produced. \\
\hline Over-run \\
\hline Legitimate product is made in excess of production agreements. i.e. underreporting production \\
\hline Simulation \\
\hline $\begin{array}{l}\text { Illegitimate product is designed to look like but not exactly copy the legitimate products. These } \\
\text { constitute of fraudulent products of a lesser quality. }\end{array}$ \\
\hline
\end{tabular}

Using the beef supply chain map published by Brooks et al., (2017), area(s) in the beef supply chain where the fraud report occurred were identified. Although 32 areas were identified in the original map, as seen in Figure 1, reports were re-categorized into 26 possible areas. These areas are too detailed to be identified in RASFF and HorizonScan but have been based on the information given in the RASFF and HorizonScan reports, the type of fraud identified, and knowledge of the supply chain. Repeated areas such as, auction, direct (private) sell, and storage were condensed and put in the same category. Importing and exporting was also condensed and categorized into the same area. Lastly, rearing and fattening/finishing were categorized as 
farming. Rearing generally refers to the breading and raising of livestock, this is followed by a short but intensive feeding period before slaughter, known as fattening/ finishing (Dictionary, 2002). For this review, rearing and fattening/ finishing were merged into a common area of 'farming' as databases do not lend information to determine whether a fraudulent report occurred in the rearing or the fattening/finishing stages. Fraud that occurred before an animal was slaughtered occurred in the farming stage, this includes the use of unapproved veterinary

The non- discriminatory nature of the RASFF and HorizonScan databases meant that further assumptions had to be made based on information from RASFF notification or HorizonScan reports, along with the application of the author's industry knowledge. The assumptions are summarised below:

- Primary processing includes the slaughter of the animal and the removal of the fifth quarter (Brooks et al., 2017). Fifth quarter is a term used by the beef industry to refer to non-carcass meat. It includes all products harvested from the carcass in the abattoir including: offal such as liver, kidneys, heart, tongue, heads, cheek meat, skirt, and tail; edible co-products such as fat, hooves, stomachs/tripe, intestinal runners/sausage casings; and animal by-products which can include intestinal contents and the hide (Walsh, 2014). Any fraud which occurred in meat that had not been further processed was considered to have occurred in the primary processing stage.

- Secondary processing includes the boning, cutting, mining, dicing, packaging, labelling and further processing of the meat, before it is distributed to retail market or for further processing. Primary and secondary processing may be on different sites (in another off site facility) but also may occur on the same site. This is dependent on the capability of 
the processor. As secondary processing is where fraud on processed meats occurs unless otherwise stated in the review.

- Animal by-products category 1 and category 2 refer to high risk materials that cannot be used in the human or animal food chain and therefore must be destroyed. Category 1 includes, carcasses and all body parts of animals that are suspected of being infected with transmissible spongiform encephalopathy (TSE), carcasses of animals used in experiments or contaminated parts of animals including contamination via illegal treatments, medicine use etc., and specified risk material (SRM) (Gov.uk, 2018). SRM is considered high risk as there is potential for prion contamination which cause TSEs and presents itself as Creutzfeldt-Jakob Disease (CJD) in humans (National Health Service, 2015; World Health Organization, 2019). Category 2 animal by-products also includes animals rejected by abattoirs due infectious diseases, carcasses containing residues from authorised treatments, carcasses of dead and diseased, carcasses of livestock discovered dead; and digestive tract content (Gov.uk, 2018).

- Animal by-products category 3 is low risk product and includes products of animal origin originally intended for human consumption but withdrawn for commercial reasons, rather than because it is unfit for humans (Gov.uk, 2018).

- Pet food category 3 refers to material that is no longer intended for human consumptions but is from animals that have passed an ante-mortem test and includes by-products such as hides, horns, collagen, gelatine or blood, and therefore, is generally fit for human consumption. However, it is more commercially viable to sell these products to other industries such as the pet food sector (Gov.uk, 2018).

- Retailer describes a business selling products to the public (British Retail Consortium, 2018). 

the home such as restaurants, take-away, delis, and cafeterias.

264

265

266

267

268

269

270

271

272

273

274

275

276

277

278

279

280

281

282

283

284 
Figure 1. Fraud reports form RASFF and HorizonScan mapped in the beef supply chain adapted from Brooks et al. 2017
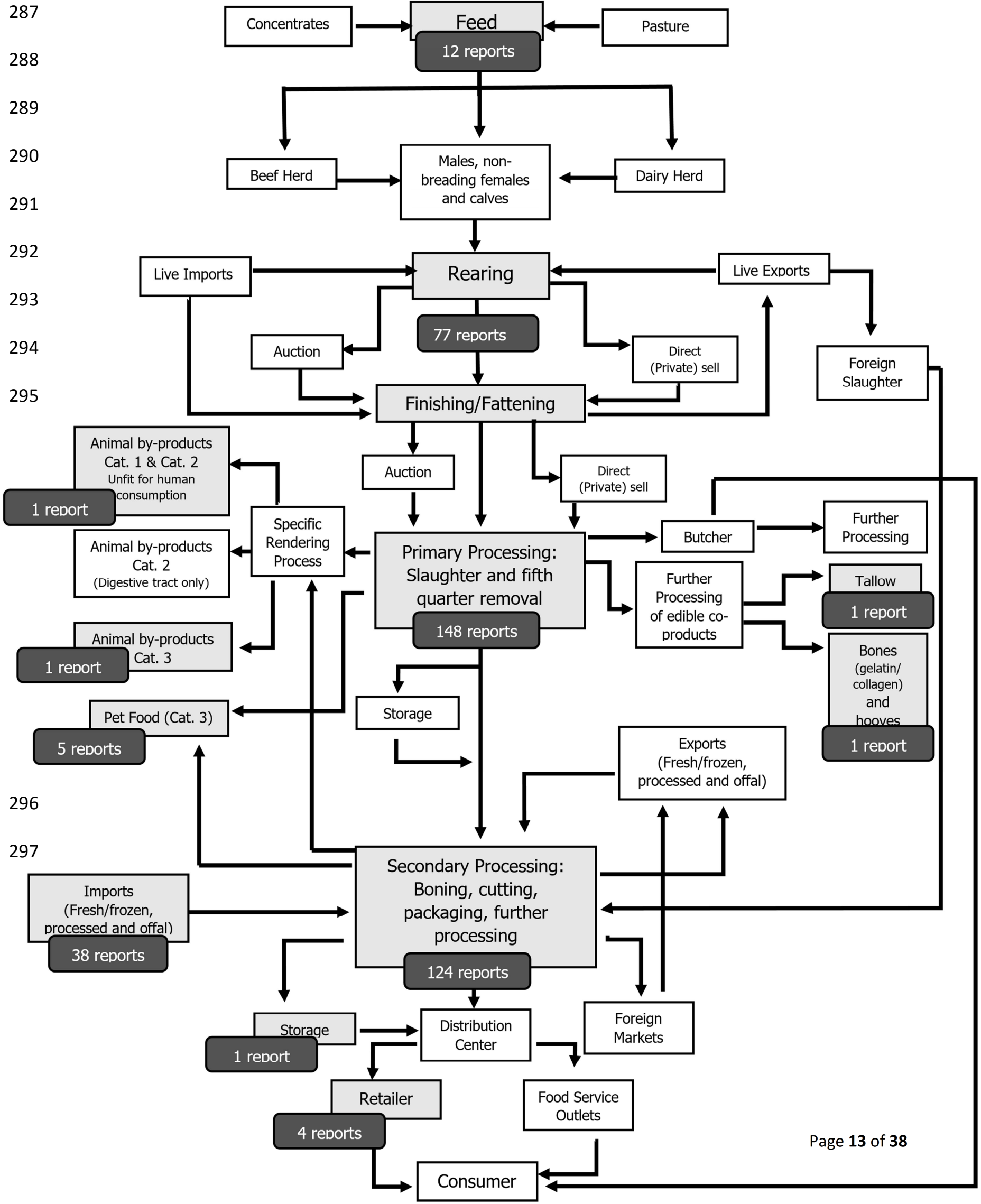


\subsection{Selection Criteria}

Following extraction and sorting of reports, the data was subjected to the following protocol to warrant inclusion:

- Reports that stated "suspected" or "attempted" fraud were excluded as it could not be deduced whether the fraudulent activity actually took place or not.

- Recorded reports must only have involved beef and beef products. Reports which stated, 'various meat products', 'red meat products' (or any variation of these), or those reports that did not clearly state that the product involved was meat originating from a bull, heifer, steer, cow or calf, were excluded. All categories of beef were included, i.e. fresh, frozen, dehydrated, canned beef etc. Products listed as 'containing beef' were only recorded if the fraudulent issue was directly attributable to the beef within the product. For example, if noodles with dehydrated beef was listed as a report and beef was named as the confirmed implicating product, the report was included.

- Animal feed related fraud was recorded when the feed was destined for cattle, as this could have entered the human food chain once consumed by the cattle. For inclusion, an incidence of contaminated feed had to be confirmed but did not have to be consumed by cattle, i.e. preingested and ingested contaminated feed were both considered.

- In cases where a report was documented on both RASFF and HorizonScan it was recorded once.

- $\quad$ Residues were only recorded if illegal veterinary medical products or growth promoters were found. Legal residues found over the maximum residue limit were not included as this may not be intentional and therefore it may not be fraudulent. 
319

320

321

322

323

324

325

326

327

328

329

330

331

332

333

334

335

336

337

338

339

340

341

\subsection{Analysis}

Following the application of selection criteria to the data, an analysis was conducted on the included reports to determine threats to the beef supply chain and identify the vulnerable areas within the supply chain. Results are presented by:

- Fraud by type and area in the beef supply chain.

- Patterns in incidences over a 20-year period between 1997 and 2017, and included, 1) number of reports by fraud type, 2) report trends by area, 3) originating country of fraud and 4) fraud reports reported at a country level.

\section{Results}

\subsection{Overview}

A total of 413 food fraud reports were identified in the beef supply chain using RASFF and HorizonScan.

If the same report was found on RASFF and HorizonScan, one of the reports was deleted. Thirty-seven of the 413 reports overlapped due to multiple fraud types. Within these 413 reports, only four of the seven fraud types defined in table 1 were identified, they were: counterfeiting, adulteration, diversion, and tampering. No reports related to theft, simulation, or over-run were identified in this data. Of the recorded reports, $42.9 \%$ ( $n=177)$ were categorized as counterfeit, $41.9 \%(n=173)$ as adulteration, $9.4 \%$ $(n=39)$ as diversion and $5.8 \%(n=24)$ as tampering.

Most of the identified fraudulent reports in the beef supply chain can be attributed to counterfeiting. Counterfeiting is generally regarded to be to a trademark or patent violation (Trademark, 2020). The replication of a product or the packaging of a product are applicable examples of trademark violation. Spink and Moyer (2011) explained counterfeiting as "Copies of popular foods not produced with the 
same food safety assurances." Within this review, counterfeit product refers to beef products that have been illegally produced with the intention of mimicking or copying its legitimate counterpart. This includes products originating from unapproved premises, produced without inspection, or found to have fraudulent or missing documentation, such as entry certificates or health certificates (falsified or otherwise fraudulent documents), suggesting illegal production. Of the counterfeiting reports identified, $48.0 \%(n=85)$ were a result of production without inspection, $43.5 \%(n=77)$ as a result of fraudulent documentation and $8.5 \%(n=15)$ of reports were recorded as production on an illegal premises.

41.9\% $(n=173$ ) of reports were categorized as adulteration. Adulteration includes the addition of unknown substances to a product and/or the dilution of a product and can include a wide range of contaminants. Of the reports categorized as adulteration, $48.6 \%(n=84)$ were as a result of substitution or dilution. This can be further broken down into substitution/dilution by, species (89.2\%/ 75 reports), SRM (4.8\%/ 4 reports), water (3.6\%/ 3 reports), with animal by-products (1.2\%/ 1 reports), or fat (1.2\%/ 1 report). $47.4 \%$ ( $n=82$ ) of adulteration reports were due to illegal veterinary medicine and growth promoters. Undeclared or illegal additives and preservatives were also defined as adulteration reports and accounted for $4.0 \%(n=7)$ of reports.

9.4\% of identified fraud was categorized as diversion. Diverted products are those which were illegally imported or exported (92.1\%/35 reports), as well as the illegal sale of products (10.5\%/ 4 reports), which refers to placement of an illegal product on a legitimate market, or when a legitimate product is illegally sold through an unofficial market.

Tampering accounted for $5.8 \%(n=24)$ of identified fraud. Reports in this category comprised of fraudulent labels (58.3\%/ 14 reports), expiry date changes (33.3\%/8 reports) and product up-labelling 
(8.3\%/ 2 reports). Product up-labeling is the use of an illegitimate value claim or marketing claim.

Recorded reports of up-labelled product were due to claiming a false country of origin.

\subsection{Food fraud by area of the beef supply chain}

Of the 26 identified areas in the beef supply chain, 12 were found to have been implicated in food fraud

reports, as illustrated in Figure 1. The number of reports found by area of the supply chain and the types of reports in each area are summarized in Table 2 . The majority of fraud reports $(84.5 \%, n=349)$ were found in three main areas of the chain; primary processing, secondary processing and farming. These areas are critical in the supply chain, as all other areas in the supply chain emerge from these. This is significant as any fraud originating at any of the three core areas could easily be transmitted to all other stages of the beef supply chain. The remaining $15.5 \%(n=64)$ of reports were found in the remaining nine areas. import/export, feed, pet food, retailer, animal by products category 1 and category 2 , animal by products category 3, further processing of bone, hooves and tallow, and storage. 
Table 2. RASFF and HorizonScan data of fraud reports in the beef supply chain by type and area

390

\begin{tabular}{|c|c|c|c|}
\hline $\begin{array}{l}\text { Area in the beef supply } \\
\text { chain }\end{array}$ & Fraud Type & $\begin{array}{c}\text { Number of } \\
\text { reports }\end{array}$ & $\begin{array}{c}\text { Percentage of total } \\
\text { reports }\end{array}$ \\
\hline \multirow{3}{*}{ Primary processing } & Adulteration & 2 & $0.5 \%$ \\
\hline & Counterfeiting & 144 & $34.9 \%$ \\
\hline & Tampering & 2 & $0.5 \%$ \\
\hline \multirow{3}{*}{ Secondary processing } & Adulteration & 75 & $18.2 \%$ \\
\hline & Counterfeiting & 28 & $6.8 \%$ \\
\hline & Tampering & 21 & $5.1 \%$ \\
\hline Farming & Adulteration & 77 & $18.6 \%$ \\
\hline \multirow{4}{*}{ Import/ Export } & Adulteration & 1 & $0.2 \%$ \\
\hline & Counterfeiting & 1 & $0.2 \%$ \\
\hline & Diversion & 35 & $8.5 \%$ \\
\hline & Tampering & 1 & $0.2 \%$ \\
\hline Feed & Adulteration & 12 & $2.9 \%$ \\
\hline \multirow{2}{*}{ Pet food } & Adulteration & 4 & $1.0 \%$ \\
\hline & Counterfeiting & 1 & $0.2 \%$ \\
\hline Retailer & Diversion & 4 & $1.0 \%$ \\
\hline $\begin{array}{l}\text { Animal by-products cat. } 1 \& \\
\text { cat. } 2\end{array}$ & Adulteration & 1 & $0.2 \%$ \\
\hline Animal by-products Cat. 3 & Adulteration & 1 & $0.2 \%$ \\
\hline $\begin{array}{l}\text { Further processing: Bone } \\
\text { and hooves }\end{array}$ & Counterfeiting & 1 & $0.2 \%$ \\
\hline Storage & Counterfeiting & 1 & $0.2 \%$ \\
\hline Tallow & Counterfeiting & 1 & $0.2 \%$ \\
\hline \multicolumn{2}{|c|}{ Total Reports } & 413 & $100 \%$ \\
\hline
\end{tabular}

391

392

\subsubsection{Primary Processing Reports}

Primary processing was found to be the most vulnerable area within in the beef supply chain, with approximately $35.9 \%(n=148)$ of reports occurring in this area. The main type of fraud which occurred was counterfeiting (34.9\%/ 144 reports), with $81.4 \%$ of all counterfeiting reports across the supply chain occurring at the primary processing stage. The remaining reports in this area were categorized as adulteration and tampering, each contributing $0.5 \%(n=2)$ of fraud reports to primary processing. All adulteration at primary processing were attributable to water substitution ( $1.3 \%$ / 2 reports). Water is added to increase weight of the product and therefore increasing profit for the perpetrator (Ballin, 
400

401

402

403

404

405

406

407

408

409

410

411

412

413

414

415

416

417

418

419

420

421

422

2010). Although species substitution is the most common types of substitution as discussed above, it was completely absent in this area. Species substitution would be difficult to conceal at point of slaughter; therefore, the absence of species substitution would be as expected at primary processing.

\subsubsection{Secondary Processing Reports}

$30.0 \%(n=124)$ of identified reports occurred at secondary processing stage. The largest variety of fraud occurred in this area, with adulteration identified as the biggest threat in this area, accounting for $60.5 \%$ $(n=75)$ of identified reports. The majority of adulteration at secondary processing was due to species substitution $(88.0 \% / \mathrm{n}=66)$. The different species of meat concealed as beef included, horse (in a variety of meatballs, burgers, lasagnes, tortellini and sausage pork) and a combination of chicken and pork.

Water and fat substitution each accounted for 1 report (1.3\%). The remaining 9.3\% ( $n=7)$ of adulteration reports in secondary processing was due to the use of illegal or undeclared additives and preservatives, and included colorants (to conceal substitution) and bleach (to remove stains on meat).

$22.6 \%(n=75)$ of reports in secondary processing were due to counterfeiting. These reports were comprised of $53.6 \%$ ( $n=15)$ of products produced without inspection, $39.3 \%(n=11)$ due to fraudulent documents and $7.1 \%(n=2)$ produced on an unapproved premises. Lastly, tampering in this area accounts for $16.9 \%(n=21) .47 .6 \%(n=10)$ of tampering in this area was due to fraudulent labels, $38.1 \%$ $(n=8)$ from changes in expiry information and $14.3 \%(n=3)$ product-up labelling.

\subsubsection{Farming Reports}

$100 \%$ of reports related to fraud at the farming stage were due to use of illegal veterinary medicine or growth promoters in cattle, administered through feed or intravenously. Of total reports involving 
illegal veterinary medicine or growth promoters throughout the supply chain, the farming stage accounted for $93.9 \%(n=77)$ of these reports. The remaining $6.1 \%(n=5)$ of reports were found in animal feed.

\subsection{Chronological analysis by fraud type}

Food fraud reports in the beef supply chain between 1997 and 2017 are illustrated in Figure 2. The top line on the graph indicates the total number of fraud reports in the beef supply chain between 1997 and 2017. However, the first report of fraud was not recorded until 2001.

\section{Figure 2. Chronology of fraud reports found on RASFF and HorizonScan by fraud type}

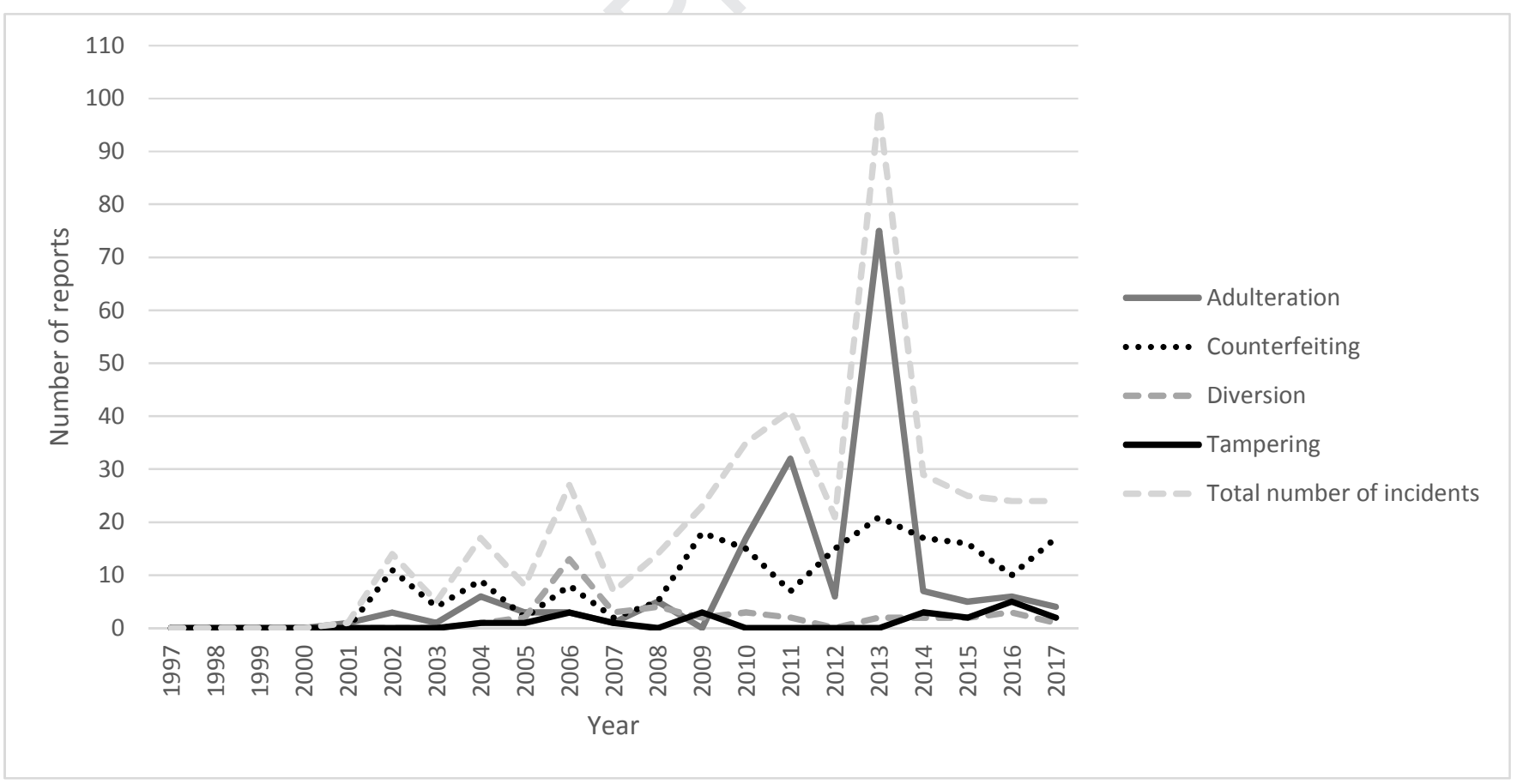

The largest proportion of reports, (23.7\% of total reports), was reported in $2013.51 .6 \%(n=213)$ of fraud in the 20-year period (from 1997 to 2017) occurred between 1997 and 2012. Between 2014 and 2017, 
24.7\% ( $n=102$ ) of total fraud occurred; ranging from 5.8\%-7.0\% (2014- 29 reports; 2015-25 reports; 2016-24 reports; 2017-24 reports). As shown in Figure 2, total fraud reports vary by year. However, post 2013, fraud is consistently higher than before the peak of reports reported in 2013.

The highest amount of adulteration reports occurred in 2013. 78.1\% $(n=75)$ of these reports were due to adulteration and $43.4 \%$ of all adulteration reports across the 20 -year period occurred in 2013 . The majority of fraud in 2013 was due to species substitution (80.0\%). the remaining $20 \%$ ( $n=15)$ were a result of illegal veterinary drugs and growth promoters use $(n=13)$, water substitution $(n=2)$ and fat substitution ( $n=1)$. The second highest reports of adulteration reports occurred in 2011, accounting for $18.5 \%(n=32)$ of all adulteration reports between 1997 and 2017, and were all a results of illegal use of veterinary drugs and growth promoters.

Trends associated with adulteration reports are volatile, Figure $\mathbf{2}$ illustrates dramatic peaks and troughs. Counterfeiting is more consistent and has more reports recorded over the 20-year period than adulteration. The first reports of counterfeiting were reported in RASFF in 2011 and between 2011 and 2017 counterfeiting reports were reported every year, peeking in 2013 , where $27.3 \%(n=21)$ of counterfeiting reports occurred. $90.5 \%(n=19)$ of counterfeiting reports were due to fraudulent documentation and the remaining $9.5 \%$ was shared between production on an illegal premises $(n=1)$ and production without inspection $(n=1)$.

$33.3 \%$ of all diversion occurred in 2006, all of which were a result of illegal import or export. $20.8 \%(n=4)$ of tampering occurred in 2016 and these reports were a result of expiry changes (50\%/ 2 reports) and product up-labelling (50\%/ 2 reports). This was the only year in which product up-labelling was identified. 
462

463

464

465

466

467

470

471

472

473

474

475

476

477

478

479

480

481

482

483

484

485

\subsection{Chronological analysis of fraud by supply chain area}

As primary processing, secondary processing, and farming had the highest amount of identified fraud reports $(84.5 \%, n=349)$, these areas have been trended by date (Figure 3). The largest increase of reports was observed in secondary processing in 2013. In 2013 15.1\% ( $n=62)$ of all reports occurred in secondary processing. These reports make-up $50.0 \%$ of all reports which occurred in secondary processing in the 20-year period reviewed. Fraud found in secondary processing was consistently higher after 2013. Between 2014 and 2017, 31.5\% (n=39) of fraud occurred at secondary processing, before 2013 , between $1997-2012$, only $19.4 \%(n=24)$ of reports were in secondary processing.

Reports at primary processing were consistently higher than in secondary processing throughout the 20year period. The most reports at primary processing occurring also in 2013 (14.9\%, n=22). There was also a sharp increase in reports at primary processing in 2009 , accounting for $12.8 \%$ ( $n=19$ ) of all reports in this area.

The first report in farming occurred in 2001. The most significant increase occurred in 2011, where $41.6 \%(n=32)$ of all farming reports occurred. This correlates with an increase in adulteration reports in 2011 (Figure 2), as these reports were due to adulteration via illegal veterinary medicine and growth promoters.

(1) 
Figure 3. Chronology of fraud reports found on RASFF and HorizonScan by area

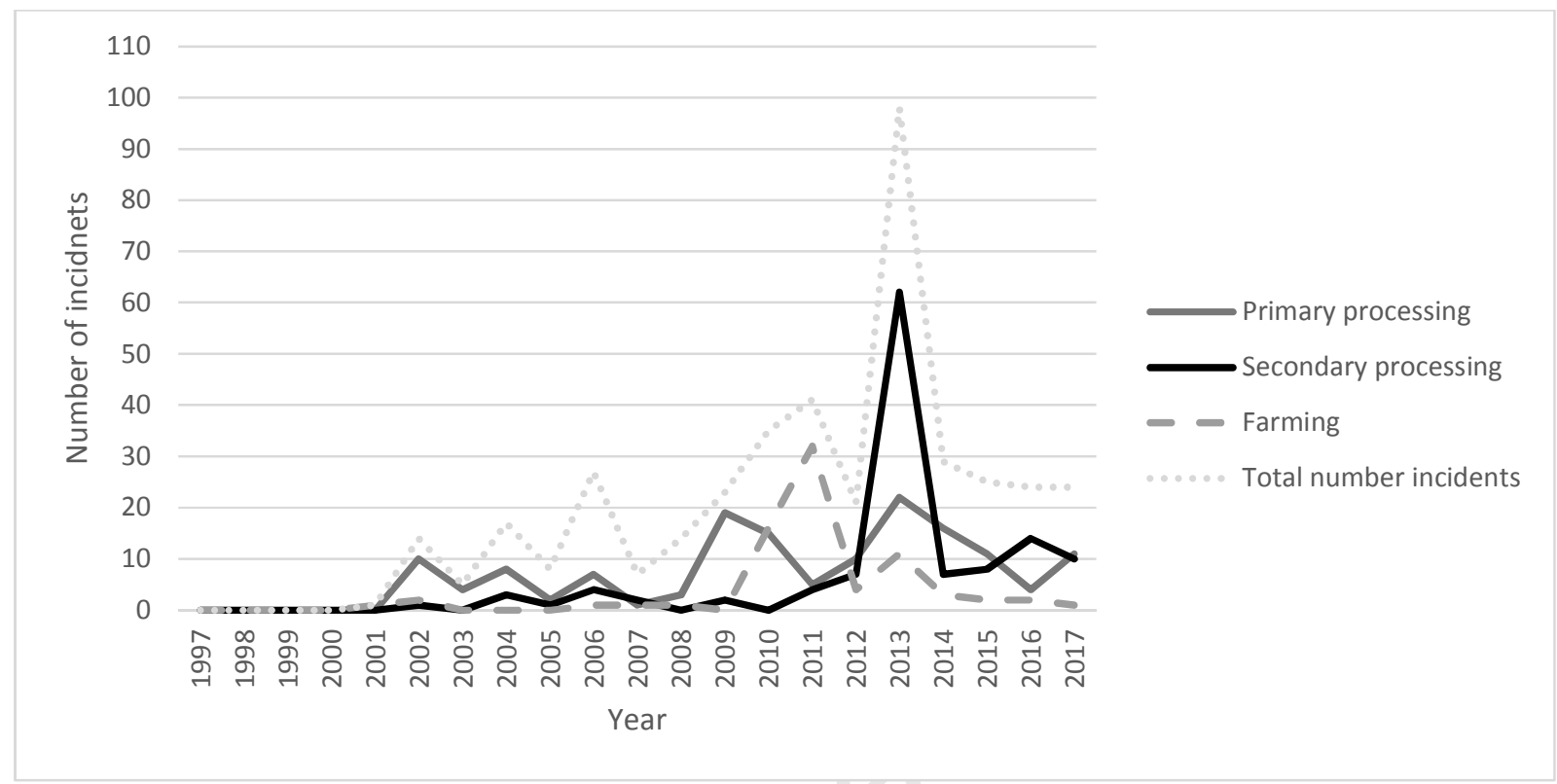

\subsection{Country of origin and country of notification}

\subsubsection{Country of Origin Trends}

The food fraud reports identified are believed to have originated from 45 countries. For 8 of the reports, the country of origin was unknown or not stated. Figure 4 trends the top 5 counties where most reports originated: Brazil, the United States, Germany, Poland and the United Kingdom. 65.2\% ( $n=232$ ) of reports originated from these 5 countries. The most amount of reports originated from Brazil (20.1\%, $n=83)$, of which $69.9 \%(n=58)$ were a result of adulteration, where $96.6 \%$ of the adulterants were the presence of illegal veterinary drugs and growth promoters, and the $3.4 \%(n=2)$ of reports were result of illegal or undeclared additives or preservatives. 


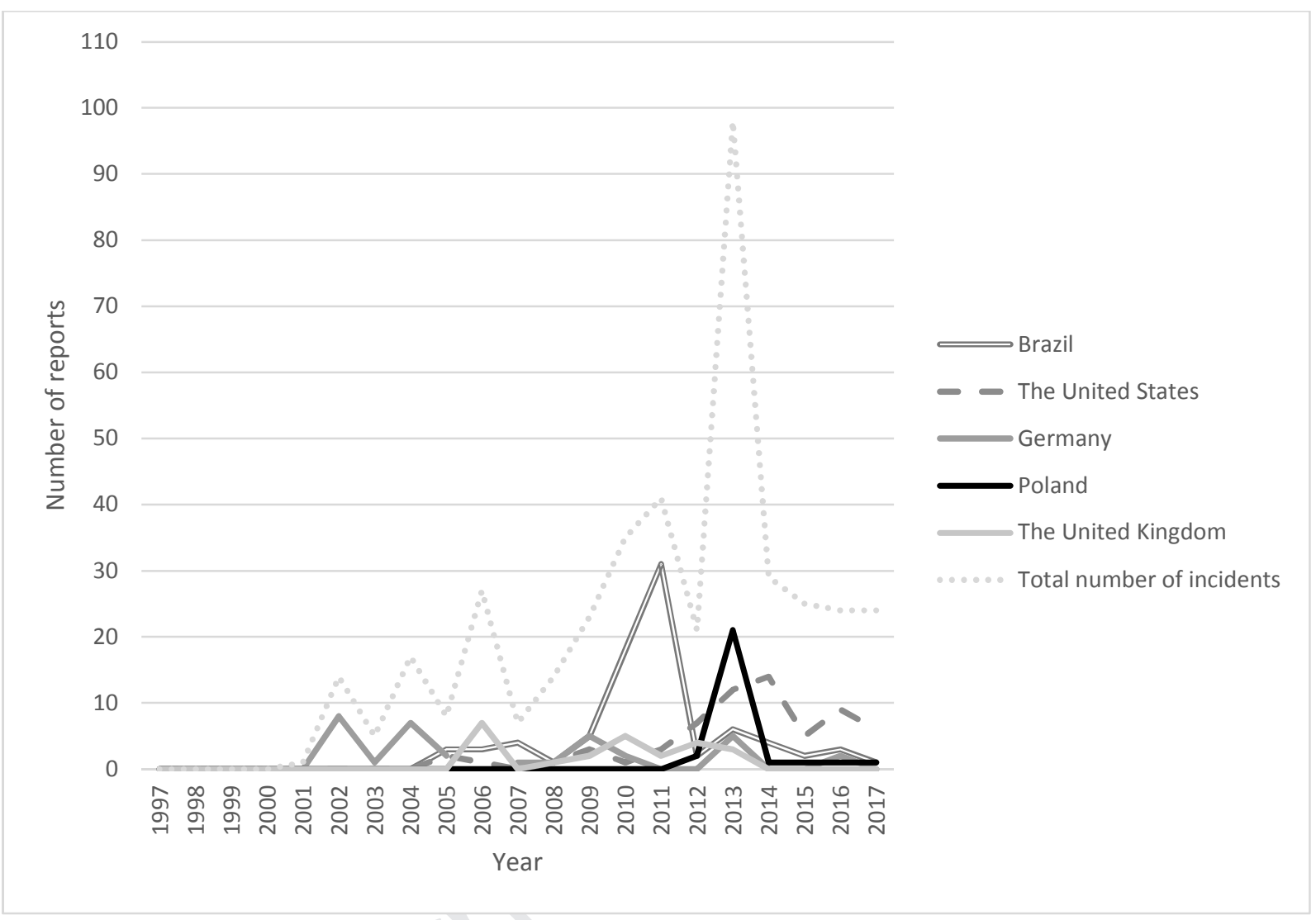

504

505

$15.2 \%(n=64)$ of reports originated in the United States (US), of which $85.9 \%(n=55)$ were due to counterfeiting. Twenty-seven (49.1\%) of those counterfeiting reports were due to production without an inspection; 26 (47.3\%) were a result of issuing fraudulent health certificates, documentation, or markings, and $2(3.6 \%)$ were a consequence of production on unapproved premises. $6.3 \%(n=4)$ of US related reports were a result of adulteration and $50 \%(n=2)$ of that adulteration was due to the addition of approved additives. Further,1 (25\%) adulteration report was due to species substitution, and another $(25 \% / n=1)$ was due to the use of illegal veterinary medicine or growth promoters. Tampering events in the US accounted for $4.7 \%(n=3)$ of incidents, of which $2(67 \%)$ were a result of changing of expiry information, and $33 \%(n=1)$ was a consequence of incorrect or fraudulent label use. The smallest level of 
US originating fraud $(3.1 \% / \mathrm{n}=2)$ was due to diversion, specifically illegal import or export of beef and/or beef products.

Germany accounted for $8.2 \%(n=34)$ of reports, of which $70.6 \%(n=24)$ were a result of counterfeiting. Of the counterfeiting reports an overwhelming amount (95.8\%/ 23 of the 24$) n=23$ ) were due to production without an inspection, and remaining $1(4.2 \%)$ was a result of fraudulent health certificates. $17.6 \%(n=6)$ of the reports related to Germany were due to adulteration, all of which were a consequence of species substitution. The remaining $11.8 \%$ of German reports were diversion $(n=2)$, (specifically illegal sales) and tampering $(n=2)$. Of the 2 tampering reports, one was a consequence of changed expiration information and the other related to the use of fraudulent labels.

Reports originating from Poland accounted for $6.5 \%(n=27)$ of reports. The majority of these reports $(85.1 \% / n=23)$ were due to adulteration, of which $87 \%(n=20)$ were a consequence of species adulteration, $8.7 \%(n=2)$ were a result of addition (specifically unapproved additives), and $4.3 \%(n=1)$ was due to the use of illegal veterinary medicine or growth promoters. Of the Polish reports, $7.4 \%(n=2)$ were due to c counterfeiting, specifically fraudulent health certificates, and $3.7 \%(n=1)$ was due to diversion via illegal sales, and the remaining 3.7\% was a result of tampering (creating fraudulent labels).

UK originating reports accounted for $5.8 \%(n=24)$ of total reports. $75.0 \%(n=18)$ of these reports were due to counterfeiting, of which $88.9 \%(n=16)$ was due to production without inspection, $5.6 \%(n=1)$ were a result of fraudulent health certificates and $5.6 \%(n=1)$ from production of beef/ beef products on an unapproved premises. Three (12.5\%)reports were due to diversion via illegal import and export, two (8.3\%) from adulteration via species substitution and one report (4.2\%) of tampering with expiration information. 


\subsubsection{Country of Notification Trends}

Notification reporting of fraud reports came from 38 counties plus 1 notification from the EU. Figure 5 illustrates trends from the top 5 fraud notifying countries in the beef supply chain between 1997 and 2017. These were Germany, UK, US, Japan and Italy, which reported $53.3 \%(n=220)$ of all identified fraud.

Germany reported the most fraud reports $13.3 \%(n=55)$ of all recorded reports. $50.9 \%(n=28)$ of these reports were due to counterfeiting, $43.6 \%(n=24)$ were a result of adulteration and $5.5 \%(n=3)$ were a consequence of diversion. The majority fraud reported by Germany $(52.7 \%, n=29)$ also originated from Germany. Germany reported the most fraud reports in 2013 (9 reports), and all of these reports were due to adulteration, specifically species adulteration. Significant increases in fraud notifications from Germany also occurred in 2002, 2004, 2008 and 2010, where 8 notifications where recorded in each year.

The most fraud in the UK was reported in 2011, which accounted for $32.7 \%$ (16 reports) of all notifications from the UK in the 20-year time period from 1997 to $2017.87 .5 \%(n=14)$ of these notifications in 2011 referred to reports origination from Brazil, all for which were a consequence of adulteration via the use of illegal veterinary medicine and growth promoters. The remaining $12.5 \%(n=2)$ of reports were a result of in-country reports, i.e. they originated from (and notified by) the UK. Overall, $44.9 \%(n=22)$ of all fraud notified by UK also originated from the UK.

The US first notified a fraud report in 2008, when 1 notification of counterfeit product originated from the US. The most number of notifications in the US were made in 2015 , where $28.9 \%(n=13)$ of all US notifications reported were a result of counterfeiting, closely followed by in 2014 when $26.7 \%(n=12)$ of 

no Italian notifications. Of the reports notified $9.4 \%(n=3)$ originate from Italy itself.

notifications were made all pertaining to counterfeit products. In 2014, the US was both the notifying and originating country. $71.1 \%$ ( $n=32$ ) of notifications made by the US also originated from the US.

The first notifications made by Japan occurred in 2009 . Of the 39 notifications made by Japan, $97.4 \%$ ( $n=38)$ were categorized as counterfeiting, (specifically fraudulent or missing documentation), with the remaining $2.6 \%(n=1)$ of reports due to adulteration by means of water substitution. An increase in notifications made by Japan was detected in 2013 , accounted for $41.0 \%$ ( $n=16)$ of Japanese notifications. All notifications made by Japan in 2013 were reports of counterfeiting, most originating from the US (68.8\%/11 reports), with the remainder originating from France (18.8\%/ 3 reports) and the Netherlands (12.5\%/2 reports). Another increase in notifications (23.1\%) from Japan was seen in 2017, where 9 reports related to counterfeit products. Unlike Germany, the US and the UK, Japan did not self-notify any fraud. Of the reports reported by Japan, most originated from the US (59.0\%, 23 reports).

The highest number of notifications from Italy was in $2010(28.1 \%, n=9)$. Seven $(77.8 \%)$ of the 9 reports in 2010 were due to adulteration, with the remaining $2(22.2 \%)$ attributable to diversion. $77.8 \%$ of these 9 reports cases originated from Brazil; 6 reports were a result of adulteration via the use of illegal veterinary medicine and growth promoters, 1 report of diversion, and 2 reports (22.2\%) of species substitution (from Pakistan, in the form of sheep casing declared as bovine, then illegally exported to Brazil). Italy reported a high level of reports in 2006 (25.0\%/8 reports). All of these reports were due to diversion via illegal imports. Of these 2006 reports, $71.4 \%(n=5)$ originated from the Philippines and the 28.6\% $(n=2)$ from China. All reports notified by Italy occurred between 2003 and 2015, with an average 1 to 2 reports reported per year, excluding aforementioned reports in 2006 and in 2009 when there were 


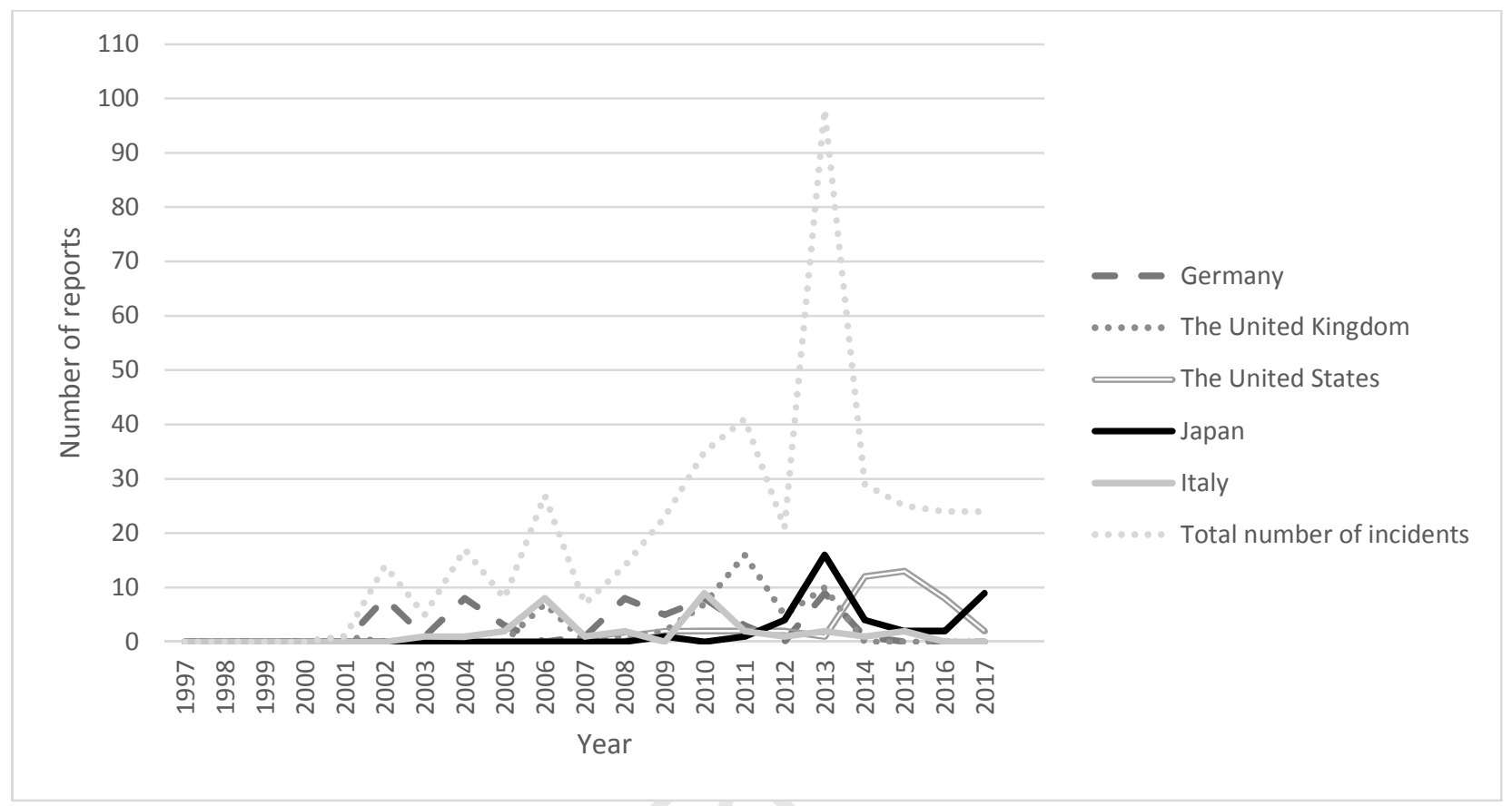

\section{Discussion}

591

592

\subsection{General}

To date, no other published literature has focused on trending and analyzing historical food fraud in the beef supply chain over a 20-year period; this article has addressed this gap. Related research includes, Tähkäpää and associates (2015) assessment of food fraud cases in the EU and Finland using RASFF and notifications from The Finnish Food Safety Authority (Evira). This analysis focused on reports between 2008 - 2012 and was not limited to a specific commodity. Tähkäpää et al., (2015) identified 44 reports pertaining to meat and meat products (other than poultry), from 14 fraud types related to meat and meat products, and $29.5 \%$ of these fraudulent reports were due to illegal or unauthorized trade/ import/ transit. In this review, the reports identified by Tähkäpää at al., (2015) would have been categorized as 'diversion' which only accounted for $9.2 \%$ of reports based on the analysis. The discrepancy in reports from RASFF and HorizonScan may be a result of differences in the time spans 
602

603

604

605

606

607

608

609

610

611

612

613

614

615

616

617

618

619

620

621

622

623

624

investigated, how fraud type was defined, or because Tähkäpää et al., (2015) investigated a more extensive range of commodities. Tähkäpää et al. (2015) found 9.1\% of food fraud in meat was due to "adulteration/ tampering," these reports would have been classified as "adulteration" in this review which was found responsible for $41.9 \%$ of fraud in meat and meat products. This may be a consequence of the Horsemeat Scandal of 2013 which was not included in Tähkäpää et al. (2015) analysis.

\subsubsection{Types of fraud in the beef supply chain}

Counterfeiting, as defined in this review, consists of processing/production on an unapproved premises production, without inspection, or with fraudulent or missing documentation, including fraudulent or lack of traceability documents, entry records or health certificates. Counterfeiting was found to be the biggest threat to the beef supply chain, as most of the reports were recorded in this category.

Production on unapproved premises also suggests that there are parallel supply chains working illegally, outside of the realm of the legitimate beef industry. Counterfeit products are a threat to the food industry and public health as it is unlikely these products undergo the required standard of hygiene or quality checks, therefore significantly increasing risk of a food safety outbreak (Moore, Spink and Lipp, 2012). Consequently, the beef industry would likely experience economic downturn due to immediate costs of product recall, but also longer term impact of consumer distrust in the industry, potentially impacting sales across the supply chain as a whole, affecting legitimate and illegitimate actors alike.

No identified reports were categorized as theft, over-run, or simulation. As such reports have been defined by prominent researchers and inferred as occurring within other food supply chains, it is likely that current detection methods are not sufficient within this supply chain for the necessary detection (Spink \& Moyer, 2011; 2013). Furthermore, due to the lack of definition for food fraud and the 
ambiguity around types of fraud, it is possible that these theft, over-run and simulations are not being captured by RASFF and HorizonScan.

\subsubsection{Vulnerable areas in the beef supply chain}

Primary processing was found to be the most vulnerable area in the beef supply chain, with reports largely due to counterfeiting. This suggests that these counterfeiting reports are not happening within the legitimate beef industry, which is well regulated through legislative requirements, third-party accreditations and customer requirements. Illegitimate processors can damage the reputation of an entire supply chain, and are a threat to public health, the consumer and the beef industry. However, these risks still apply to the legitimate industry, as reports at farming level will ultimately enter the beef industry at this stage. Issues relating to farming are discussed below.

\section{Based on findings, secondary processing is the most vulnerable area for the beef industry. A large} number of reports (30.0\%/ 124 reports) were identified in this area, as well as a large variety of reports. Secondary processing is an area where incoming products from other companies and countries enter the beef industry supply chain, making it an area of vulnerability for the industry.

All reports found in farming were due to illegal veterinary medicine and growth promoter use. Residues from the veterinary medicine and growth promotors will persist through the concurrent stages of the beef supply chain, thereby posing a threat to public health. Health effects caused by veterinary drugs and growth promoters may differ depending on the substance. The major concern associated with use of antimicrobials in animals is the development of antimicrobial resistance in humans, making it difficult to treat infections (Baynes et al., 2016). Other effects include blood dyscrasias and cancer (Baynes et al., 2016). As there are a large variety of substances which could be administered and subsequently mixed 
651

652

653

654

655

656

657

658

659

660

661

662

663

664

665

666

667

668

669

670

671

672

in various ways, it makes detection problematic. Consequently, ongoing use of illegal veterinary medicine and growth promoters is a significant risk to the beef supply chain.

\subsubsection{Trends in food fraud in the beef supply chain}

Trending of reports in the beef supply chain suggests that fraud is continually happening. As a consequence of more regular and improved testing, detection and awareness, more fraud is uncovered. This is evidenced around 2013, where the highest levels of reported fraud occurred which coincided with the Horsemeat Scandal. After 2013, fraud reports were consistently higher than they were before 2013 , in the 20-year period from 1997-2017. It could be argued that the threat posed by food fraud was realized after the Horsemeat Scandal, and as a result testing increased. The first report of fraud was reported in 2001, however food fraud can be traced back to the Roman times, therefore it is likely that fraud was occurring in the beef industry well before 2001 (Shear,2010). In 2001, the EU implemented a cattle testing program in response to the Bovine Spongiform Encephalopathy (BSE) crisis (Pickrell, 2006), and the resulting increase in testing could explain the increase in fraud detection.

An increase in adulteration attributed to illegal veterinary drugs and growth promoters is seen in 2011.

This coincides with the 2011 World Health Organization (WHO) selected antimicrobial resistance as the theme for World Health Day (Leung, Weil, Raviglione, \& Nakatani, 2011), which increased public awareness, triggering an overhaul of regulations and the use of antibiotics in food producing animals (Gilbert, 2012). It could be argued that this increase in awareness resulted in an upsurge in testing, and therefore, greater detection of the use of illegal veterinary drugs.

Differences in the levels of notifications by country and fraud originating from countries may be occurring due to differences in legislation between countries, as well as a result of differences in type 
and frequency of authenticity testing. Further, these differences could be attributable to the amount of beef produced among countries and also the differences in the quantity of beef imported/ exported to/from countries. The majority of reported food fraud incidences across RASFF and HorizonScan originated from Brazil. However, Brazil did not notify any reports of fraud. This could be a result of different controls and legislation related to the reporting of food fraud incidences in different countries.

\subsection{Limitations to identified food fraud reports}

Due to the concealed nature of food fraud, the actual frequency of occurrence is unknown (Manning and Soon, 2016; Moore, Spink and Lipp, 2012; Spink and Moyer, 2011). Reputable sources such as RASFF and HorizonScan are essential in providing a better understanding of food fraud trends and occurrences. However, it is unlikely that all cases of food fraud in the global beef supply chain are captured in RASFF and HorizonScan. It is crucial to consider that there will be reports of food fraud that will remain undetected or unrecorded. It can be assumed that more fraud incidents are occurring than declared and that all types of fraud are occurring. The scale and type of fraud continually change, therefore fraudsters can continue to operate under the radar and remain undetected, further contributing to detection difficulties. An inability to detect these diffuse and oblique acts of fraud skews the data. Further bias may be introduced into data as RASFF is not genuinely global as this is only required by EU member states.

The lack of a formal food fraud definition and lack of formally defined types of food fraud leaves room for assumptions to be made. RASFF and HorizonScan do not offer a guide for addressing how reports are described, and it could be assumed that personnel entering the data must use personal judgment to determine if a report is food fraud and this prone to subjectivity. This same assumption can be made for authors on this review when categorizing reports into fraud types. Fraud types are not well defined for 
697

698

699

700

701

702

703

704

705

706

707

708

709

710

711

712

713

714

715

716

717

718

719

720

the beef supply chain, leaving ambiguity where authors must use their best judgment. This has pointed out the need for an official protocol and definitions to be set for fraud types so that it can be more accurately documented and trended.

With available resources, this review has created a better understanding of the trends in food fraud in the beef supply chain and highlights the need for a global repository to capture record and recall global food fraud cases. Future work should help facilitate a more accurate means of trending and presenting this type of data, as well as focus on developing strategic detection and prevention procedures and methods for the beef industry, based on the findings of this review.

\section{Conclusion}

This review aimed to increase understanding of the different types of fraud that occur in the beef supply chain. In addition, it highlighted the areas in the supply chain that are the most susceptible to fraud.

This information helps to foster a better understanding on how to defend the supply chain and protect legitimate actors as well as consumers from fraud. Counterfeiting and adulteration were found to be the biggest threat to the beef supply chain in relation to fraud type. The most vulnerable area was found to be primary processing, followed by secondary processing and farming. As these are considered core areas of the supply chain, as a result, all subsequent areas of the beef supply chain are at risk of being impacted by fraud. However in-depth analysis of detection and prevention measures within the beef supply chain is needed to create a more holistic understanding of vulnerabilities. Furthermore, an analysis of suspected fraud discussed in the media and scholarly sources is important, as it is unlikely that all fraud reports can be detected via traditional means. These endeavours combined with this review will aid understanding and allow for the development of targeted detection and prevention methods in the beef supply chain. 
721

722

723

724

725

726

727

728

729

730

731

732

733

734

735

736

737

738

739

740

741

742

743

744

Acknowledgements

This EIT Food activity has received funding from the European Institute of Innovation and Technology (EIT), a body of the European Union, under Horizon2020, the EU Framework Programme for Research and Innovation.

EIT Food is Europe's leading agri-food innovation initiative, with the aim to create a sustainable and future-proof food sector. The initiative is made up of a consortium of key industry players, start-ups, research centres and universities from across Europe. EIT Food aims to collaborate closely with consumers to develop new knowledge and technology-based products and services that will ultimately deliver a healthier and more sustainable lifestyle for all European citizens.

Special thanks to ABP Food Group for offering knowledge and funding to this review in order to gain a better understanding of food fraud occurring in the beef supply chain.

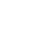

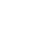




\section{References}

Amchova, P., Kotolova, H., \& Ruda-Kucerova, J. (2015). Health safety issues of synthetic food colorants. Regulatory Toxicology and Pharmacology, 73(3), 914-922. 10.1016/j.yrtph.2015.09.026.

Baynes, R. E., Dedonder, K., Kissell, L., Mzyk, D., Marmulak, T., Smith, G., \& Riviere, J. E. (2016). Health concerns and management of select veterinary drug residues. Food and Chemical Toxicology, 88, 112-122. doi.org/10.1016/j.fct.2015.12.020.

Bouzembrak, Y., \& Marvin, H. J. P. (2016). Prediction of food fraud type using data from rapid alert system for food and feed (RASFF) and bayesian network modelling. Food Control, 61, 180-187. 10.1016/j.foodcont.2015.09.026.

Bouzembrak, Y., Steen, B., Neslo, R., Linge, J., Mojtahed, V., \& Marvin, H. J. P. (2018). Development of food fraud media monitoring system based on text mining. Food control, 93, 283-296. doi.org/10.1016/j.foodcont.2018.06.003.

Bosley, C. (2007). German kebab sales slump after rotten meat scandal. Reuters. Retrieved February 4 2020 from: http://www.reuters.com/article/idUSLA76533220070903

Brooks, S., Elliott, C. T., Spence, M., Walsh, C., \& Dean, M. (2017). Four years post-horsegate: An update of measures and actions put in place following the horsemeat report of 2013. Npj Science of Food, 1(1), 5. 10.1038/s41538-017-0007-z.

British Retail Consortium (BRC) (2018). Global Food Safety Issue 8. BRC Global Standards London.

Cawthorn, D., Steinman, H. A., \& Hoffman, L. C. (2013). A high incidence of species substitution and mislabelling detected in meat products sold in South Africa. Food Control, 32(2), 440-449. 10.1016/j.foodcont.2013.01.008

Cook, R. (2018). World Beef Production: Ranking of Countries. Retrieved 13 March, 2019, from http://beef2live.com/story-world-beef-production-ranking-countries-0-106885.

Djekic, I., Jankovic, D., \& Rajkovic, A. (2017). Analysis of foreign bodies present in European food using data from rapid alert system for food and feed (RASFF). Food Control, 79, 143-149. 10.1016/j.foodcont.2017.03.047.

Dictionary.com (2002). Rearing. Retrieved January 14, 2020, from https://www.dictionary.com /browse/rearing.

Elliott, C. (2014). Elliott Review into the Integrity and Assurance of Food Supply Networks-Final Report: A National Food Crime Prevention Framework. HM Government. Retrieved 13 March, 2019, from https://www.gov.uk/government/publications/ elliott-review-into-the-integrity-and-assuranceof-food-supply-networks-final-report. 
European Food Safety Authority. (2010). Establishment and maintenance of routine analysis of data from the Rapid Alert System on Food and Feed. EFSA Journal, 8(1), 1449. 10.2903/j.efsa.2010.1449

European Commission (EC). (2009). 30 years of keeping consumers safe: The rapid alert system for food and feed of the European Union. Luxembourg: Office for Official Publications of the European Communities. Retrieved13 March, 2019, from https://ec.europa.eu/food/sites food/files/safety/docs/rasff_30_booklet_en.pdf.

European Commission (EC).(2018) Food Fraud. Retrieved 13 March, 2019, from https://ec.europa.eu/food/safety/food-fraud_en

European Union. (2017). RASFF - The Rapid Alert System for Food and Feed - 2016 annual report. Luxembourg: Publications Office of the European. Retrieved 13 March, 2019, https://ec.europa.eu/food/sites/food/files/safety/docs/rasff_annual_report_2016.pdf

Food and Environment Research Agency (FERA). (2018). HorizonScan Global Food Integrity and Risks System. Retrieved 14 March, 2019, from https://www.fera.co.uk/media /wysiwyg/HorizonScan_Leaflet.pdf

Food Standards Agency (FSA). (2017). Chapter 19-Specified Risk Material. Meat Industry Guide. Retrieved 13 March, 2019, from https://www.food.gov.uk/sites/default /files/media/document/chapter19-srm.pdf.

Green, M. (2018). Fake organics and decade-old meat: Belgian scandal details revealed. IEG Vu Agribusiness intelligence. Retrieved 13 March, 2019, from https://iegvu.agribusinessintelligence.informa.com/CO217269/Fake-organics-and-decadeoldmeat-Belgian-scandal-details-revealed

Grobe, S.(2018). Scandal over rotten meat in Belgium. Euronews.com. Retrieved 13 March, 2019, from https://www.euronews.com/2018/03/12/scandal-over-rotten-meat-in-belgium.

Gov.uk.(2018) Guidance: Animal by-product categories, site approval and disposal. Retrieved 13 March, 2019, https://www.gov.uk/guidance/animal-by-product-categories-site-approval-hygiene-anddisposal.

Gilbert, N. (2012). Rules tighten on use of antibiotics on farms: clampdown aims to stop spread of drugresistant microbes. Nature, $481(7380), 125-126$.

Hayneys, B. \& Spagnuol, S. (2017). Brazil police raid BRF and JBS meat plants in bribery probe. Retrieved 13 March, 2019, from https://www.reuters.com/article/us-brazil-corruption-food/brazil-policeraid-brf-and-jbs-meat-plants-in-bribery-probe-idUSKBN16O1LH.

Huck, C. W., Pezzei, C. K., \& Huck-Pezzei, V. A. (2016). An industry perspective of food fraud. Current Opinion in Food Science, 10, 32-37. doi.org/10.1016/j.cofs.2016.07.004

Jia, C., \& Jukes, D. (2013). The national food safety control system of China-a systematic review. Food Control, 32(1), 236-245. doi.org/10.1016/j.foodcont.2012.11.042. 
Johnson, R. (2014). Food fraud and economically motivated adulteration of food and food ingredients. Congressional Research Service.

Leung, E., Weil, D., Raviglione, M., \& Nakatani, H. (2011). WHO / the WHO policy package to combat antimicrobial resistance World Health Organization. Retrieved 13 March, 2019, from http://www.who.int/bulletin/volumes/89/5/11-088435/en/

Leuschner, R. G. K., Hristova, A., Robinson, T., \& Hugas, M. (2013). The rapid alert system for food and feed (RASFF) database in support of risk analysis of biogenic amines in food. Journal of Food Composition and Analysis, 29(1), 37-42. 10.1016/j.jfca.2012.09.004.

Manning, L. (2016). Food fraud: Policy and food chain. Current Opinion in Food Science, 10, 16-21. 10.1016/j.cofs.2016.07.001

Manning, L., \& Soon, J. M. (2014). Developing systems to control food adulteration. Food Policy, 49(Part 1), 23-32. 10.1016/j.foodpol.2014.06.005

Manning, L., \& Soon, J. M. (2016). Food safety, food fraud, and food defense: a fast evolving literature. Journal of food science, 81(4), R823-R834. doi.org/10.1111/1750-3841.13256

Manning, L., Smith, R., \& Soon, J. M. (2016). Developing an organizational typology of criminals in the meat supply chain. Food Policy, 59, 44-54. 10.1016/j.foodpol.2015.12.003

Marvin, H. J., Bouzembrak, Y., Janssen, E. M., van der Fels-Klerx, H. J., van Asselt, E. D., \& Kleter, G. A. (2016). A holistic approach to food safety risks: Food fraud as an example. Food research international, 89, 463-470. doi.org/10.1016/j.foodres.2016.08.028

Moore, J. C., Spink, J., \& Lipp, M. (2012). Development and application of a database of food ingredient fraud and economically motivated adulteration from 1980 to 2010. Journal of Food Science, 77(4), R118-R126. doi.org/10.1111/j.1750-3841.2012.02657.x

National Health Service. (2015). Symptom: Creutzfeldt-jakob disease. NHS.uk. Retrieved 12 March, 2019, from https://www.nhs.uk/conditions/creutzfeldt-jakob-disease-cjd/

Pickrell, J. (2006). Timeline: BSE and VCJD. Retrieved 13 March, 2019, from https://www.newscientist.com/article/dn9926-timeline-bse-and-vcjd/.

PricewaterhouseCoopers (PwC). (2017). Food fraud vulnerability assessment. Retrieved February 4, 2020, from https://www.pwc.com/gx/en/services/food-supply- integrity-services / food-fraudvulnerability-assessment.html

Regan, Á, Marcu, A., Shan, L. C., Wall, P., Barnett, J., \& McConnon, Á. (2015). Conceptualising responsibility in the aftermath of the horsemeat adulteration report: An online study with Irish and UK consumers. Health, Risk \& Society, 17(2), 149-167. 10.1080/13698575.2015.1030367

Shears, P. (2010). Food fraud-a current issue but an old problem. British Food Journal, 112(2), 198-213. doi.org/10.1108/00070701011018879 
Spink, J. (2014). GFSI Direction on Food Fraud and Vulnerability Assessment (VACCP). Michigan State University. Retrieved 13 March, 2019, from http://foodfraud.msu.edu/2014/05/08/gfsidirection-on-food-fraud-and-vulnerability-assessment-vaccp/

Spink, J., \& Moyer, D. C. (2011). Defining the public health threat of food fraud. Journal of Food Science, 76(9), R163. 10.1111/j.1750-3841.2011.02417.x

Spink, J., Moyer, D. C., \& Speier-Pero, C. (2016). Introducing the food fraud initial screening model (FFIS). Food Control, 69, 306-314. 10.1016/j.foodcont.2016.03.016.

Tähkäpää, S., Maijala, R., Korkeala, H., \& Nevas, M. (2015). Patterns of food frauds and adulterations reported in the EU rapid alert system for food and feed and in Finland. Food Control, 47, 175184. 10.1016/j.foodcont.2014.07.007.

Trademark Counterfeiting: Everything You Need to Know. (2020). Retrieved January 15, 2020, from https://www.upcounsel.com/trademark-counterfeiting.

van Ruth, S. M., Huisman, W., \& Luning, P. A. (2017). Food fraud vulnerability and its key factors. Trends in Food Science \& Technology, 67, 70-75. 10.1016/j.tifs.2017.06.017.

Walsh, C. (2104). The use of Animal by products: The improving opportunities to add value to the beef and sheep slaughtering sectors. EBLEX. Retrieved 10 March, 2019 from https://beefandlamb.ahdb.org.uk/wp-content/uploads/2016/07/74318-5th-Quarter-Use-andFlow-Final-Report-130514.pdf.

World Health Organization. (2019). Transmissible spongiform encephalopathies (TSE). WHO.int. Retrieved 19 March, 2019 from https://www.who.int/bloodproducts/tse/en/.

Zhang, W., \& Xue, J. (2016). Economically motivated food fraud and adulteration in China: An analysis based on 1553 media reports. Food Control, 67, 192-198. doi.org/10.1016/j.foodcont.2016.03.004.

Walsh, C. (2104). The use of Animal by products: The improving opportunities to add value to the beef and sheep slaughtering sectors. EBLEX. Retrieved 10 March, 2019 from https://beefandlamb.ahdb.org.uk/wp-content/uploads/2016/07/74318-5th-Quarter-Use-andFlow-Final-Report-130514.pdf.

World Health Organization. (2019). Transmissible spongiform encephalopathies (TSE). WHO.int. Retrieved 19 March, 2019 from https://www.who.int/bloodproducts/tse/en/.

Zhang, W., \& Xue, J. (2016). Economically motivated food fraud and adulteration in China: An analysis based on 1553 media reports. Food Control, 67, 192-198. doi.org/10.1016/j.foodcont.2016.03.004. 
Highlights

- 413 fraud incidents in the beef supply chain were identified between 1997-2017.

- Counterfeiting and adulteration each accounted for $42.9 \%$ of identified fraud.

- Primary processing is the most vulnerable, accounting for $35.8 \%$ of incidents. 


\section{Conflict of Interest and Authorship Conformation Form}

We confirm that there is no conflict of interest for all authors involved in this review. The manuscript has been read and approved by all named authors and that there are no other persons who satisfied the criteria for authorship but are not listed. We further confirm that the order of authors listed in the manuscript has been approved by all of us.

Submission of an article implies that the work described has not been published previously that it is not under consideration for publication elsewhere

We understand that the Corresponding Author is the sole contact for the Editorial process. He/she is responsible for communicating with the other authors about progress, submissions of revisions and final approval of proofs.

Yours sincerely,

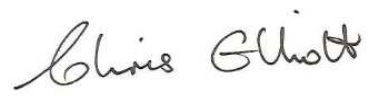

\section{Professor Christopher Elliott}

Corresponding Author

Director of the Institute for Global Food Safety 